\title{
Analysis of lanthanide induced NMR shifts using a crystal field independent method: application to complexes of tetraazamacrocyclic ligands
}

\author{
Jimin Ren ${ }^{\text {a }}$, Shanrong Zhang ${ }^{\mathrm{a}}$, A. Dean Sherry ${ }^{\mathrm{a}, \mathrm{b}}$, Carlos F.G.C. Geraldes ${ }^{\mathrm{c}, *}$ \\ ${ }^{a}$ Department of Chemistry, The University of Texas at Dallas, PO BOX 830688, Richardson, TX 75083-0688, USA \\ ${ }^{\mathrm{b}}$ Department of Radiology, The Mary Nell and Ralph B. Rogers Magnetic Resonance Center, University of Texas Southwestern Medical Center, 5801 \\ Forest Park Rd., Dallas, TX 75235-9085, USA \\ ${ }^{\mathrm{c}}$ Department of Biochemistry, Faculty of Science and Technology, and Center of Neurosciences, University of Coimbra, 3000 Coimbra, Portugal
}

Received 12 November 2001; accepted 13 March 2002

Dedicated in honor of Professor Helmut Sigel

\begin{abstract}
The linear graphical analysis of the LIS NMR data available for the axially symmetric complexes $[\operatorname{Ln}(\mathrm{DOTA})]^{-}\left(\mathbf{M}^{-}\right.$and $^{\mathbf{m}}$ isomers), $[\operatorname{Ln}(\mathrm{DOTP})]^{5-}\left(\mathrm{pH} 10.0,7.0\right.$ and 3) and $[\operatorname{Ln}(\text { DOTEA })]^{3+}$ using the classical crystal field dependent method and a crystal field independent method were compared. As the second method provides ratios of geometric structural terms $G$ rather than $G$ values, the effect of lanthanide contraction was reduced. Thus, the large breaks in plots observed for all nuclei of those systems using the classical method are still present in the plots of the second method, only in a few of the nuclei and much reduced. This shows that the large breaks at the middle of the lanthanide series present in plots of the classical method as well as the anomalies often present for those plots for the Tm and Yb ions are mostly due to changes of the crystal field coefficient $A_{2}{ }^{0}\left\langle r^{2}\right\rangle$ along the lanthanide series, while both the hyperfine coupling constants and the ratios of geometric terms also change as a result of the lanthanide contraction, leading to small breaks at the middle of the lanthanide series. Analysis of the proton shifts of [Ln(DOTP)] complexes at pH 10, 7 and 3 indicates that protonation of the complexes results in a decrease on the crystal field coefficient. The dipolar shift ratios and absolute shifts obtained were also interpreted in terms of the structural models for those complexes in solution and their available Xray crystal structures.
\end{abstract}

(C) 2002 Elsevier Science B.V. All rights reserved.

Keywords: Azamacrocycles; Lanthanide; NMR study

\section{Introduction}

The binding of a ligand to a paramagnetic $\mathrm{Ln}^{3+}$ ion is well known to generally result in large NMR frequency shifts at the ligand nuclei located in the vicinity of the metal center [1], which depend on both the nature of the $\mathrm{Ln}^{3+}$ ion and the location of the nucleus relative to the metal center. In most cases, these lanthanide-induced shifts (LIS) are very sensitive to structural changes associated with changes in $\mathrm{pH}$, temperature and counter-ions, allowing the lanthanide complexes to be used

* Corresponding author. Tel.: +351-239-85 3609; fax: +351-299-85 3609

E-mail address: geraldes@ci.uc.pt (C.F.G.C. Geraldes). for many purposes, such as elucidation of molecular conformation [2,3], resolution of enantiomers [4], detection of coordinated water numbers of lanthanide complexes [5], simplification of NMR spectra [6], separation of transmembrane cation resonances $[7,8]$ and temperature probes in biological systems [9-11].

LIS values generally arise from a combination of the Fermi contact and dipolar or pseudo-contact interactions, which can be conveniently expressed as follows for a complex with effective axial symmetry (threefold or higher) $[1,3,12]$ :

$$
\Delta_{a, i}=F_{a}\left\langle S_{z}\right\rangle_{i}+D_{i}\left(A_{2}{ }^{0}\left\langle r^{2}\right\rangle\right)_{i} G_{a}
$$

where the contact contribution to the LIS $\left(\Delta_{a, i}\right)$ depends 
on $F_{a}$ values, which are proportional to the hyperfine coupling constant $A_{a}$ of a given ligand nucleus $a$, and on the spin expectation value $\left\langle S_{z}\right\rangle_{i}$ for a given paramagnetic lanthanide ion $i$, while the dipolar shift is a function of the magnetic anisotropy constant $D_{i}$ characteristic of the lanthanide complex (proportional to the anisotropy of the magnetic susceptibility tensor of the complex along the $z$ axis $\left(\chi_{z z}-1 / 3 \operatorname{Tr} \chi\right)$ and to Bleaney's constant, $C_{j}$ ), the ligand field coefficient of the complex $\left(A_{2}^{0}\left\langle r^{2}\right\rangle_{i}\right)$, and the geometric factor of ligand nucleus $a$, $G_{a}\left(=\left(3 \cos ^{2} \theta-1\right) / r^{3}\right)$ describing the position of that nucleus relative to the $\mathrm{Ln}^{3+}$ through the $\mathrm{Ln}^{3+}$-nucleus distance $r$ and the angle $\theta$ between $r$ and the main symmetry axis of the complex. Theoretical $\left\langle S_{z}\right\rangle$ and $D$ values are available in the literature for the $\mathrm{Ln}^{3+}$ ions [13-16].

Since the dipolar term contains the geometric information of interest, any quantitative structural analysis requires a reliable separation of the observed shift into the contact and dipolar terms. The proposed empirical separation methods rely on measurement of LIS data for a group of lanthanide complexes [17,18]. The LIS separation is then achieved based on the following assumptions: (1) the hyperfine coupling constants, $A_{a}$ (and thus the $F_{a}$ values) the geometric factors, $G_{a}$, and the crystal field parameter, $A_{2}{ }^{0}\left\langle r^{2}\right\rangle$, are invariant along the lanthanide series; and (2) the theoretical $\left\langle S_{z}\right\rangle$ and $D$ values reported for the $\mathrm{Ln}^{3+}$ aqueous ions are valid for all complexes. As suggested by Reilley et al. [18], under these conditions the values of $F_{a}$ and of the product $\left(A_{2}^{0}\left\langle r^{2}\right\rangle\right)_{i} G_{a}$ could be evaluated from the observed shift using Eq. (1). However, most frequently $F_{a}$ and $\left(A_{2}^{0}\left\langle r^{2}\right\rangle\right)_{i} G_{a}$ are obtained by linear regression of plots based on rearrangement of Eq. (1) into two linear equations:

$$
\begin{aligned}
& \Delta_{a, i} /\left\langle S_{z}\right\rangle_{i}=F_{a}+G_{a}\left(A_{2}^{0}\left\langle r^{2}\right\rangle\right)_{i} D_{i} /\left\langle S_{z}\right\rangle_{i} \\
& \Delta_{a, i} / D_{i}=F_{a}\left\langle S_{z}\right\rangle_{i} / D_{i}+G_{a}\left(A_{2}^{0}\left\langle r^{2}\right\rangle\right)_{i}
\end{aligned}
$$

In these cases it can be concluded that the $\mathrm{Ln}^{3+}$ complexes are isostructural and the crystal field coefficient is invariant along the lanthanide series. However, a separation of the lanthanide ions into two subgroups, with a break at $\mathrm{Gd}^{3+}$, is frequently observed when the LIS for a series of closely related complexes are plotted according to the two above equations. It has been demonstrated by simulations that the smooth lanthanide contraction (ionic radii of the $\mathrm{Ln}^{3+}$ ions decrease across the series from 1.36 to $1.17 \AA$ ) results in a break in a plot according to Eq. (2), whereas a plot according to Eq. (3) has no significant break [19]. Probably in the first case the effect of the gradual change of $G_{a}$ factors is amplified by the division by $\left\langle S_{z}\right\rangle_{i}$, a parameter which is relatively large for $\mathrm{Gd}-\mathrm{Er}$. However, such breaks could also arise if $F_{a}$ values [17] and/or the crystal field parameter $A_{2}{ }^{0}\left\langle r^{2}\right\rangle$ [20] varied along the lanthanide series. We have recently shown for $[\operatorname{Ln}(\text { DOTP })]^{5-}$ complexes (DOTP ${ }^{8-}$ : 1,4,7,10-tetraazacyclododecane1,4,7,10-tetrakis (methyle-ne phosponate)) that the crystal field parameter $A_{2}^{0}\left\langle r^{2}\right\rangle$ indeed changes along the later half of lanthanide series $(\mathrm{Tb}-\mathrm{Yb})$ with a maximum observed for $\mathrm{Tm}^{3+}$ [21]. Based on Reuben's crystal field parameter independent method for the LIS data analysis [20], the following equation, involving the shifts of two nuclei $a$ and $b$ can be deduced:

$\Delta_{a, i}=\left(F_{a}-R_{a b} F_{b}\right)\left\langle S_{z}\right\rangle_{i}+R_{a b} \Delta_{b, i}$

allowing the value of the geometric ratio $R_{a b}=G_{a} / G_{b}$ to be obtained without resort to Bleaney's constants and crystal field parameters. As long as one of the ligand nuclei is free of contact shift, the hyperfine coupling constant of other ligand nuclei can be obtained from Eq. (4). This can also be rearranged to give:

$\Delta_{a, i} /\left\langle S_{z}\right\rangle_{i}=\left(F_{a}-R_{a b} F_{b}\right)+R_{a b} \Delta_{b, i} /\left\langle S_{z}\right\rangle_{i}$

Since Eq. (5) does not depend on crystal field parameters, a plot of $\Delta_{a} /\left\langle S_{z}\right\rangle$ versus $\Delta_{b} /\left\langle S_{z}\right\rangle$ is linear with slope $R_{a b}$ and intercept $\left(F_{a}-R_{a b} F_{b}\right)$ if there is no change in the hyperfine coupling constants and the complexes are isostructural [22]. Any deviation from linearity for such plots along the lanthanide series can be safely ascribed to structural changes affecting $R_{a b}$ (and thus $G_{a}$ and $G_{b}$ ). Application of Eq. (5) to triplestranded helicates based on ligands $\mathrm{L}$ and $\mathrm{L}^{\prime}$, containing two $\mathrm{Ln}(\mathrm{III})$ ions, $\left[\mathrm{Ln}_{2}(\mathrm{~L}-2 \mathrm{H})_{3}\right]^{6+}$, or one $\mathrm{Ln}(\mathrm{III})$ ion and one $\mathrm{Co}\left(\mathrm{II}\right.$ or III) ion, $\left[\mathrm{LnCo}\left(\mathrm{L}^{\prime}\right)_{3}\right]^{5 / 6+}$, in which the $\mathrm{Ln}$ (III) are firmly held in rigid nine-coordinate tricapped trigonal prismatic sites, indeed show only straight lines along the complete lanthanide series $(\mathrm{Ln}=\mathrm{Ce}-\mathrm{Yb})$, in agreement with isostructural behaviors, although previous analyses of the data according to Eqs. (2) and (3) had shown systematic breaks between $\mathrm{Ln}=\mathrm{Eu}$ and $\mathrm{Tb}$ which had been attributed to abrupt variations of $F_{a}$ and $A_{2}{ }^{0}\left\langle r^{2}\right\rangle$ near the middle of the series [23,24]. If $F_{a}$ values change, but shift ratios $R_{a b}$ remain constant, two parallel lines are observed in plots according to Eq. (5), as found for a series of cryptate complexes [22].

In the past decade several 1,4,7,10-tetraazacyclododecane-based macrocyclic $\operatorname{Ln}($ III) complexes have found remarkable applications in Biomedicine, Biology and NMR spectroscopy $[1-3,7,8]$, amongst which the development of [Gd(DOTA) ${ }^{-}$(DOTA $^{4-}:$ 1,4,7,10-tetraazacyclododecane-1,4,7,10-tetraacetate) into a clinical MRI contrast agent and of $\left[\mathrm{Tm}(\mathrm{DOTP})^{5-}\right]$ as one of the most successful ${ }^{23} \mathrm{Na}$ NMR shift reagent for perfused organs and intact animals are some of the best examples [3,25]. This is in part a result of their special structural rigidity and unusually high thermodynamic stability and kinetic inertness, desirable properties for their in vivo applications. NMR spectroscopy has played an important role in the elucidation of the solution structures of $\mathrm{Ln}$ (III) complexes $[1,3]$. In particular, the Ln(III) complexes of 


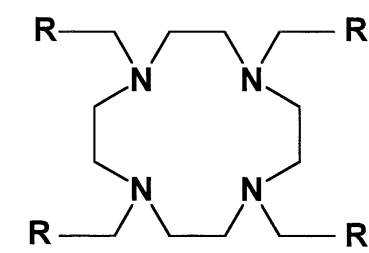

(a)
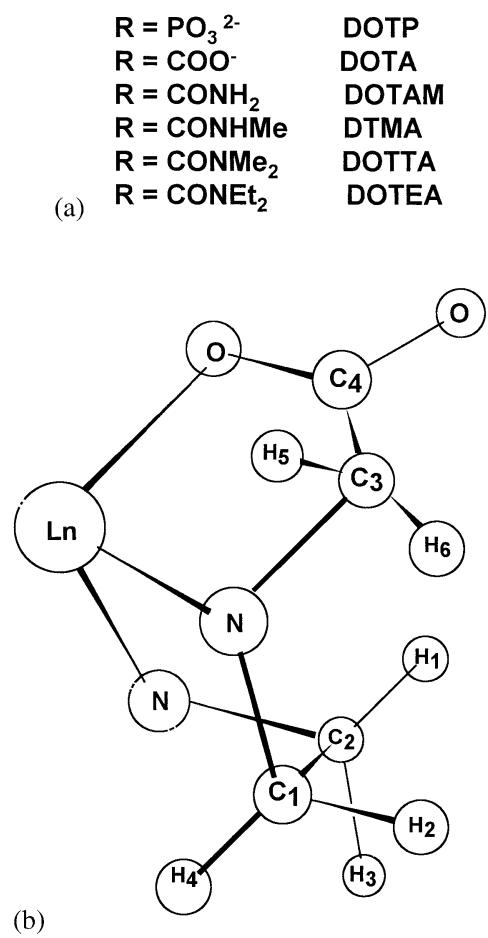

Fig. 1. (A) The chemical structures of the ligands cited in this work. (B) Model of a part of the structure of complexes in the $\Delta(\lambda \lambda \lambda \lambda)$ enantiomeric form of the $\mathbf{M}$ isomer. Symmetry-related atoms are not shown for clarity. The numbering scheme for hydrogen and carbon/ phosphorous atoms is also shown. $\mathrm{H}_{5}$ denotes the pro- $\mathrm{R}$ and $\mathrm{H}_{6}$ the pro-S pendant arm methylene proton (this notation has not always been followed $[26,35])$.

three 1,4,7,10-tetraazacyclododecane-based macrocyclic ligands, DOTP, DOTA and the DOTA-like tertiary tetraamide DOTEA (DOTEA: 1,4,7,10-tetrakis $(N, N$ diethylacetamido)-1,4,7,10-tetraazacyclodo-decane) (see structures in Fig. 1(A)), have been characterized in some detail by NMR, using plots based on Eqs. (2) and (3). The nature of breaks obtained in some of the plots, as well as abnomalies in ratios of shifts induced by $\mathrm{Tm}^{3+}$ and $\mathrm{Yb}^{3+}$ ions in the various series of complexes and their deviation form the theoretical value (2.4) anticipated for a dipolar interaction mechanism, are still not known. Our recent reanalysis of the LIS data for the DOTP complexes with the latter half-series of $\operatorname{Ln}(\mathrm{III})$ indicated that the abnormal behavior of $\mathrm{Tm}^{3+}$ in inducing ligand shifts can be explained by an exceedingly large crystal field coefficient for this metal ion relative to the other members of that half-series [21]. In the present work we extend a similar analysis to the DOTP complexes with the whole series of lanthanide ions, comparing the ${ }^{1} \mathrm{H}$ LIS values at $\mathrm{pH} 10.0,7.0$ and 3.0, and also to analogous DOTA and DOTEA complexes. The LIS analysis methods based on Eqs. (2)-(3) and Eqs. (4)-(5) are systematically compared for these systems, allowing a critical appraisal of their applicability and approximations. Finally, the dipolar shift ratios and absolute shifts obtained are interpreted in terms of structural models for those complexes in solution and their available X-ray crystal structures.

\section{Results and discussion}

${ }^{1} \mathrm{H},{ }^{13} \mathrm{C}$ and ${ }^{31} \mathrm{P}$ LIS have been reported for the series of $[\mathrm{Ln}(\mathrm{DOTP})]^{5-}$ complexes at $298 \mathrm{~K}$ in $\mathrm{D}_{2} \mathrm{O}$ at $\mathrm{pH} 10$ [26]. These complexes lack an inner-sphere water molecule, as revealed by water ${ }^{17} \mathrm{O}$ NMR shift measurements [21] and the crystal structure of the $[\mathrm{Tm}(\mathrm{DOTP})]^{5-}$ complex [22], and have four protonation steps over the $\mathrm{pH}$ range of 3-10 [28], leading to significantly $\mathrm{pH}$ dependent LIS values. Thus, besides $\mathrm{pH}$ 10 , the LIS values at $\mathrm{pH} 7$ and 3 were also analyzed. The LIS values for both ${ }^{1} \mathrm{H}$ and ${ }^{13} \mathrm{C}$ nuclei of [Ln(DOTA)] ${ }^{-}$ at $293 \mathrm{~K}$ and other temperatures in $\mathrm{D}_{2} \mathrm{O}$ at $\mathrm{pH} 7$ have also been published [29-34]. The ${ }^{1} \mathrm{H}$ and ${ }^{13} \mathrm{C}$ LIS values of the [Ln(DOTEA) $]^{3+}$ complexes in $\mathrm{CD}_{3} \mathrm{CN}$ at $253 \mathrm{~K}$ were also reported (the ${ }^{13} \mathrm{C}$ LIS data are available only for $\mathrm{Pr}, \mathrm{Nd}, \mathrm{Sm}$ and $\mathrm{Eu}$ complexes) [35]. All the above referred, previously published, LIS data analyzed in this work are listed in Table 1S. The numbering scheme for the hydrogen and carbon/phosphorous atoms is shown in Fig. 1(B), which schematically represents part of the structure of the complexes in the $\Delta(\lambda \lambda \lambda \lambda)$ enantiomeric form of the $\mathbf{M}$ isomer, where $\mathrm{H}_{5}$ denotes the pro- $\mathrm{R}$ and $\mathrm{H}_{6}$ the pro-S pendant arm methylene proton. This notation is in agreement with work for the $[\operatorname{Ln}(\mathrm{DOTA})]^{-}$complexes $[31,32]$ but the opposite of that used for $[\operatorname{Ln}(\text { DOTP })]^{5-}$ and $[\operatorname{Ln}(\text { DOTEA })]^{3+}$ $[26,35]$. Therefore, some reassignments were made in this work relative to the literature.

The eight donor atoms of these macrocyclic ligands may originate square antiprismatic eight-coordinated structures, with the four ring nitrogens defining one of the square faces in the coordination polyhedron and the four coordinated pendant arm oxygens defining the other one. The twist angle between the planes formed by the four oxygens and the four nitrogens can be positive or negative, leading to two possible isomers, the square antiprismatic (SAP) (designated $\mathbf{M}^{\prime}$ ) and the inverted SAP $\left(\mathbf{m}^{\prime}\right)$. In these two isomers, the macrocyclic rings have the same conformation and the difference between them is in the layout of the pendant arms. In these structures two structurally independent elements of chirality are present defined by the pendant arm $\mathrm{C}_{4}(\mathrm{P})-\mathrm{C}_{3}-\mathrm{N}-\mathrm{C}_{1}$ and ring $\mathrm{N}-\mathrm{C}_{1}-\mathrm{C}_{2}-\mathrm{N}$ torsion angles. The 12-membered macrocyclic ring may adopt two 
enantiomeric conformations, given as $\delta \delta \delta \delta$ and $\lambda \lambda \lambda \lambda$ (with respect to each five-membered ring chelate), and the pendant arms may be arranged in either a clockwise $(\Delta)$ or counterclockwise $(\Lambda)$ manner, leading to four possible stereoisomers. These constitute two diastereoisomers each with enantiomeric pairs which are not distinguishable by NMR spectroscopy in solution: $\mathbf{M}^{\prime}$ with enantiomers $\Lambda(\delta \delta \delta \delta)$ and $\Delta(\lambda \lambda \lambda \lambda \lambda)$, and $\mathbf{m}^{\prime}$ with enantiomers $\Delta(\delta \delta \delta \delta)$ and $\Lambda(\lambda \lambda \lambda \lambda)$ ). Only one isomer was observed in solution by ${ }^{1} \mathrm{H},{ }^{13} \mathrm{C}$ and ${ }^{31} \mathrm{P}$ NMR for the $[\operatorname{Ln}(\mathrm{DOTP})]^{5-}$ complexes, which, on the basis of the interpretation of the measured LIS values, was assigned to a SAP configuration [26], while the reported single crystal structure of the $[\mathrm{Tm}(\mathrm{DOTP})]^{5-}$ complex defines it as a single isomer $\mathbf{m}^{\prime}$ [27].

Like DOTP ${ }^{8-}$, DOTA ${ }^{4-}$ contributes eight donor atoms to a $\mathrm{Ln}^{3+}$ ion. The major structural difference between the $[\operatorname{Ln}(\text { DOTP })]^{5-}$ and $[\operatorname{Ln}(\text { DOTA })]^{-}$complexes is that the latter has two slowly interconverting diastereomers in solution [29-34]. The ${ }^{1} \mathrm{H}$ and ${ }^{13} \mathrm{C}$ NMR spectra of LnDOTA $^{-}$exhibit two sets of resonances corresponding to two coordination isomers, one set of resonances having constantly larger frequency shifts than the other group. After many studies, it was concluded that the isomer displaying larger shifts corresponds to a nine-coordinate capped (by a coordinated water molecule) CSAP structure $\mathbf{M}$, while the isomer displaying smaller shifts is either a nine-coordinate inverted CSAP m (from La to Ho), or an eightcoordinate inverted SAP $\mathbf{m}^{\prime}$ structure (Er to $\mathrm{Lu}$ ) [33]. In addition to the frequency difference, the two isomers also differ in population. The relative intensity observed for the two sets of NMR resonances showed that the $\mathbf{m}$ isomer dominates for the lighter lanthanide ions ( $\mathrm{La}-$ $\mathrm{Nd}$ ), while the $\mathbf{M}$ isomer is more highly populated for the heavier lanthanide ions $(\mathrm{Sm}-\mathrm{Lu})$ with a gradual increase of the $\mathbf{M} / \mathbf{m}$ ratio from $\mathrm{La}$ to Ho along the lanthanide series. Then, the $\mathbf{M} / \mathbf{m}^{\prime}$ population ratio decreased steadily from $\mathrm{Er}$ to $\mathrm{Lu}$. The solution structure of the CSAP isomer $\mathbf{M}$ is consistent with the $\mathrm{X}$-ray crystal structures of the $\mathrm{Eu}^{3+}, \mathrm{Gd}^{3+}, \mathrm{Y}^{3+}$ and $\mathrm{Lu}^{3+}$ complexes of DOTA, where the twist angle has a value of approximately $39^{\circ}$ [36-41]. The structure of the inverted CSAP isomer is consistent with the X-ray structures of the $\mathrm{La}^{3+}$ complex of DOTA, with a twist angle of approximately $-22^{\circ}$ [42].

Only one set of NMR signals was found in solution for the $[\operatorname{Ln}(\text { DOTEA })]^{3+}$ complexes [35]. Analysis of the observed LIS values led to a solution structure of these complexes of the CSAP (M) type, with a twist angle of $47^{\circ}$ between the planes of the $\mathrm{O}_{4}$ and $\mathrm{N}_{4}$ atoms. No crystal structure of any of these complexes is available, but the known crystal structures of $\mathrm{Ln}^{3+}$ complexes for various DOTA-like achiral primary and secondary tetramide derivatives (see Fig. 1(A)) are variable, with m structures for $\left[\mathrm{La}(\text { DOTAM })\left(\mathrm{H}_{2} \mathrm{O}\right)\right]^{3+}[43]$ and
$\left[\mathrm{Eu}(\mathrm{DOTAM})\left(\mathrm{H}_{2} \mathrm{O}\right)\right]^{3+}[44]$ (twist angles of -26.5 and $-30^{\circ}$, respectively), and $\mathbf{M}$ structures for $\left[\operatorname{Ln}(\mathrm{DTMA})\left(\mathrm{H}_{2} \mathrm{O}\right)\right]^{3+}(\mathrm{Ln}=\mathrm{Gd}$, Dy, twist angles of ca. $\left.40^{\circ}\right)[45,46]$. However, in solution it was found that the $\mathbf{m} / \mathbf{M}$ isomer ratio increased from 0.19 for $[\mathrm{Eu}(\mathrm{DOTA})]^{-}$, to 0.25 for the primary tetraamide derivative $[\mathrm{Eu}(\mathrm{DOTAM})]^{3+}$, to 0.31 for the secondary tetraamide $[\mathrm{Eu}(\mathrm{DTMA})]^{3+}$, and to 2 for the tertiary tetraamide $[\mathrm{Eu}(\mathrm{DOTTA})]^{3+}[46]$. This variation of isomer ratio agrees with the general observation that increasing steric demand at the bound metal ion favors the inverted square antiprismatic structure.

The LIS data available for the complexes were analyzed by plots according to Eqs. (2) and (3) (see Fig. 2(A) for some examples). As reported before $[26,32,35]$, many of such plots do not follow a good single linear correlation but rather divide in two subgroups with a break between light and heavy lanthanide ions. The linear correlation coefficient $R^{2}$
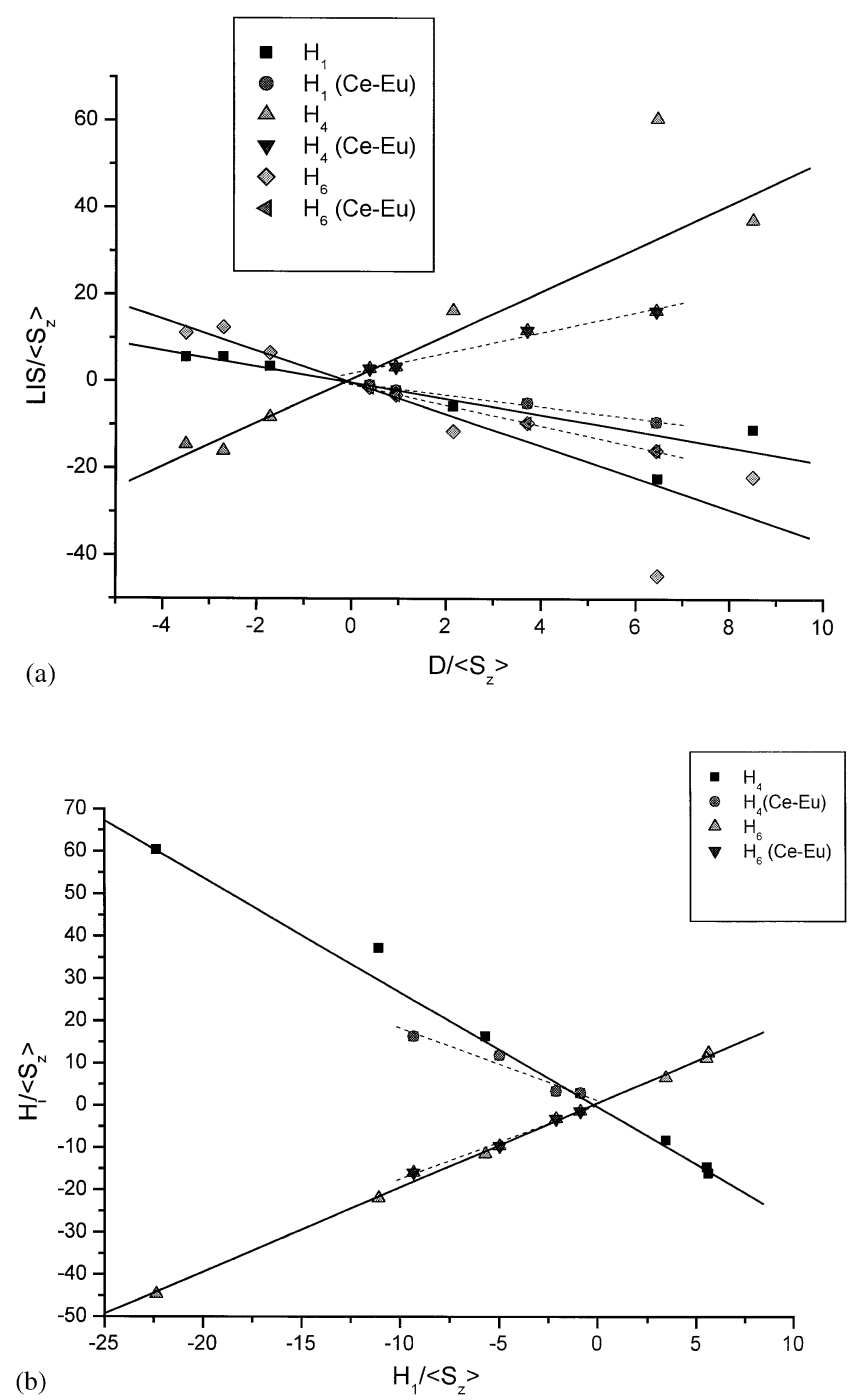

Fig. 2. Plots of observed ${ }^{1} \mathrm{H}$ data for $\mathrm{H}_{1}, \mathrm{H}_{4}$ and $\mathrm{H}_{6}$ of [ $\left.\operatorname{Ln}(\mathrm{DOTP})\right]$ (pH 7): (A) According to Eq. (2); (B) According to Eq. (5). 
and the values of $F_{a}$ and $A_{2}{ }^{0}\left\langle r^{2}\right\rangle G_{a}$ were evaluated for each proton and ${ }^{13} \mathrm{C} /{ }^{31} \mathrm{P}$ nucleus using those equations by subdivision of the lanthanides into two subgroups $(\mathrm{Ce}-\mathrm{Eu}$ and $\mathrm{Tb}-\mathrm{Yb})$ and without such a subdivision $(\mathrm{Ce}-\mathrm{Yb})$. All the protons and ${ }^{13} \mathrm{C} /{ }^{31} \mathrm{P}$ nuclei of $[\operatorname{Ln}($ DOTP $)],[\operatorname{Ln}(\text { DOTEA })]^{3+}$ and $[\operatorname{Ln}(\text { DOTA })]^{-}(\mathbf{m})$ show poor linear correlations for $(\mathrm{Ce}-\mathrm{Yb})$ data $\left(R^{2}<\right.$ 0.83 ), which, due to the breaks, improve significantly when the data is divided in two groups, although the deviations at $\mathrm{Tm}$ and $\mathrm{Yb}$ give relatively low $R^{2}$ values (e.g. $R^{2} \sim 0.71-0.89$ for $(\mathrm{Tb}-\mathrm{Yb})$ ), except for $\mathrm{H}_{1}, \mathrm{H}_{5}$ and $\mathrm{H}_{6}$ of $[\operatorname{Ln}(\text { DOTA })]^{-}(\mathbf{m})$, where the improvement is much better $\left(R^{2} \sim 0.94-0.97\right.$ for $\left.(\mathrm{Tb}-\mathrm{Yb})\right)$. $[\operatorname{Ln}(\mathrm{DOTA})]^{-}$(M) show less significant breaks, as $0.98>R^{2}>0.92$ for $(\mathrm{Ce}-\mathrm{Yb})$ does not improve much in the $(\mathrm{Tb}-\mathrm{Yb})$ data. The values of the $F_{a}$ and $A_{2}{ }^{0}\left\langle r^{2}\right\rangle G_{a}$ parameters are shown in Table $2 \mathrm{~S}$, and, for the cases studied before, agree well with previous analysis $[26,32,35]$.

The same sets of LIS data were also plotted according to Eq. (5) (see Fig. 2(B) for some examples). These plots again often do not follow a single linear correlation but show breaks between light and heavy lanthanide ions, although much less significant than those present in the plots discussed above. Thus, the values of $R^{2}$, as well as the $R_{a b}$ and $\left(F_{a}-R_{a b} F_{b}\right)$ parameters were again evaluated using that equation by subdivision of the lanthanides into two subgroups $(\mathrm{Ce}-\mathrm{Eu}$ and $\mathrm{Tb}-\mathrm{Yb})$ and without such a subdivision. Without subdivision, the $(\mathrm{Ce}-\mathrm{Yb})$ data gave poor $R^{2}$ values $(0.84-0.96)$ for $\mathrm{H}_{2}$, $\mathrm{H}_{3}, \mathrm{C}_{2}$ and $\mathrm{C}_{4} / \mathrm{P}$, good $R^{2}$ values $(0.97-0.98)$ for $\mathrm{H}_{4}$ and $\mathrm{C}_{3}$, and very good $R^{2}$ values $(>0.99)$ for $\mathrm{H}_{5}$ and $\mathrm{H}_{6}$. For all the complexes studied, $R^{2}$ values for all nuclei improved upon separation of the data in two groups (e.g. ( $\mathrm{Tb}-\mathrm{Yb}$ ) data gave $R^{2}>0.985$ in all cases), but the breaks are only statistically significant for $\mathrm{H}_{4}, \mathrm{H}_{3}, \mathrm{H}_{2}$, $\mathrm{C}_{4}$ and $\mathrm{C}_{2}$. The values of the $R_{a b}$ and $\left(F_{a}-R_{a b} F_{b}\right)$ parameters obtained are shown in Table 1.

The LIS data of the $\mathrm{Sm}^{3+}$ complexes deviate, in some cases significantly, from those of the other lanthanide complexes using Eqs.(2) and (5), in which the parameter $\left\langle S_{z}\right\rangle$ appears as the denominator, greatly influencing the goodness of the linear regression analyses and the values obtained for the parameters. It is likely that the data of the $\mathrm{Sm}^{3+}$ complexes are overweighted by Eqs. (2) and (5) due to the very small $\left\langle S_{z}\right\rangle$ value $(0.06)$ for $\mathrm{Sm}^{3+}[13,16]$. Therefore, these data were excluded from the analysis, greatly improving the linear regressions.

The values of $R_{a b}$ and of $\left(F_{a}-R_{a b} F_{b}\right)$ evaluated by the two methods, directly by Eq. (5) (Table 1) and indirectly using the $A_{2}^{0}\left\langle r^{2}\right\rangle G_{a}$ and $F_{a}$ values evaluated by Eq. (2) (Table 1S) were compared. Typical results are shown in Table 2 for the $[\operatorname{Ln}(\text { DOTP })]^{5-}(\mathrm{pH} 10)$ chelates $(\mathrm{Ce}-\mathrm{Yb})$. These show that the agreement is extremely good for all the $R_{a b}$ ratios (within an error range of $7 \%)$ and only reasonably good for the $\left(F_{a}-\right.$
$R_{a b} F_{b}$ ) values (within an error range of $23 \%$ ), due to larger errors in $F_{a}$ values obtained by Eq. (2).

In order to compare the various models of LIS analysis based on linear regressions, the five equations, Eqs. (1)-(5), were statistically assessed by analyzing the published ${ }^{1} \mathrm{H}$ LIS data for protons $\mathrm{H}_{1}-\mathrm{H}_{6}$ along the lanthanide series for the systems $[\operatorname{Ln}(\mathrm{DOTP})]^{5-}$, $[\operatorname{Ln}(\text { DOTA })]^{-}(\mathbf{M}$ and $\mathbf{m})$ and $[\operatorname{Ln}(\text { DOTEA })]^{3+}$ using the following two agreement factors [47]:

$$
\begin{aligned}
& A F(y)=\left[\sum_{a, i}\left(y_{a, i}^{\mathrm{obs}}-y_{a, i}^{\mathrm{cal}}\right)^{2} / \sum_{a, i}\left(y_{a, i}^{\mathrm{obs}}\right)^{2}\right]^{1 / 2} \\
& A F(\Delta)=\left[\sum_{a, i}\left(\Delta_{a, i}^{\mathrm{obs}}-\Delta_{a, i}^{\mathrm{cal}}\right)^{2} / \sum_{a, i}\left(\Delta_{a, i}^{\mathrm{obs}}\right)^{2}\right]^{1 / 2}
\end{aligned}
$$

where $y_{a, i}^{\text {obs }}$ and $y_{a, i}^{\text {cal }}$ are the experimental and calculated function values described by Eqs. (1)-(5), whereas $\Delta_{a, i}^{\text {obs }}$ and $\Delta_{a, i}^{\text {cal }}$ are the experimental and calculated shift values. $\Delta_{a, i}^{\mathrm{cal}}$ were calculated using Eq. (1) together with the calculated values of the $F_{a}$ and $A_{2}{ }^{0}\left\langle r^{2}\right\rangle G_{a}$ parameters (Table 2S), and Eq. (4) together with the calculated values of the $R_{a b}$ and $\left(F_{a}-R_{a b} F_{b}\right)$ parameters, without subdivision of the lanthanides into two subgroups, as described above (Table 1). Due to their over-weight in the agreement factors, the $\mathrm{Sm}^{3+}$ data were again excluded.

Table 3 compares the $A F(y)$ and $A F(\Delta)$ values obtained for $[\operatorname{Ln}(\text { DOTP })]^{5-},[\operatorname{Ln}(\text { DOTA })]^{-}$and $[\operatorname{Ln}(\text { DOTEA })]^{3+}$ and Fig. 3 shows some illustrative plots of $\Delta^{\text {obs }}$ versus $\Delta^{\text {cal }}$. These clearly indicate that, of all the five models examined, the one based on Eq. (4) gave the smallest $A F(\Delta)$ values for the four complex structures, followed by Eq. (5), which generally was better than the models based on Eqs. (1)-(3), except in the case of the $\mathbf{M}$ isomer of [ $\operatorname{Ln}($ DOTA $)]^{-}$. A comparison of the $A F(y)$ values for the three graphic models (Eqs. (2), (3) and (5)) shows that Eq. (5) is in advantage over Eqs. (2) and (3)) in describing the LIS data for all the four systems. In particular, the anomalies shown by the data of the $\mathrm{Tm}^{3+}$ complexes using models (1), (2) and (3) (see Fig. 2(A)) [26,32,35], disappear when the data are treated by Eqs. (4) and (5). This shows that the anomaly of the $\mathrm{Tm}^{3+}$ data does not result from an abrupt structural change along the second lanthanide half-series. In fact, for the $[\operatorname{Ln}(\text { DOTP })]^{5-}$ series, it has been explained by an exceedingly large crystal field coefficient for this metal ion relative to the other members of that half-series [21].

Although the statistical analysis presented should be treated with care, as the number of observations and of variables differ for the the different methods used, the fact that better statistical agreements are obtained for the methods dependent on LIS values for two nuclei, and thus with higher number of observations and of variables, making them more stringent than those based 
Table 1

Calculated $R_{a b}$ and $\left(F_{a}-R_{a b} F_{b}\right)$ parameters for the $\mathrm{Ln}^{3+}$ chelates using the graphical method based on Eq. (5)

\begin{tabular}{|c|c|c|c|c|c|c|c|c|c|c|c|c|c|c|c|c|c|c|}
\hline \multirow[t]{2}{*}{ Parameter } & \multicolumn{3}{|c|}{ DOTP (pH 10) } & \multicolumn{3}{|c|}{ DOTP (pH 7) } & \multicolumn{3}{|c|}{ DOTP (pH 3) } & \multicolumn{3}{|c|}{ DOTA (M) } & \multicolumn{3}{|c|}{ DOTA (m) } & \multicolumn{3}{|l|}{ DOTEA } \\
\hline & $\mathrm{Ce}-\mathrm{Yb}$ & $\mathrm{Ce}-\mathrm{Eu}$ & $\mathrm{Tb}-\mathrm{Yb}$ & $\mathrm{Ce}-\mathrm{Yb}$ & $\mathrm{Ce}-\mathrm{Eu}$ & $\mathrm{Tb}-\mathrm{Yb}$ & $\mathrm{Ce}-\mathrm{Yb}$ & $\mathrm{Ce}-\mathrm{Eu}$ & $\mathrm{Tb}-\mathrm{Yb}$ & $\mathrm{Ce}-\mathrm{Yb}$ & $\mathrm{Ce}-\mathrm{Eu}$ & $\mathrm{Tb}-\mathrm{Yb}$ & $\mathrm{Ce}-\mathrm{Yb}$ & $\mathrm{Ce}-\mathrm{Eu}$ & $\mathrm{Tb}-\mathrm{Yb}$ & $\mathrm{Ce}-\mathrm{Yb}$ & $\mathrm{Ce}-\mathrm{Eu}$ & $\mathrm{Tb}-\mathrm{Yb}$ \\
\hline$R_{21}$ & -0.52 & $-0.34^{\mathrm{a}}$ & -0.54 & -0.51 & $-0.27^{\mathrm{a}}$ & -0.53 & -0.49 & $-0.02^{\mathrm{a}}$ & -0.51 & -0.36 & $-0.27^{\mathrm{b}}$ & -0.37 & -0.36 & $-0.42^{\mathrm{a}}$ & -0.37 & -0.40 & -0.65 & -0.33 \\
\hline$R_{31}$ & -0.42 & $-0.21^{\mathrm{a}}$ & -0.44 & -0.41 & $-0.15^{\mathrm{a}}$ & -0.43 & -0.39 & $0.10^{\mathrm{a}}$ & -0.41 & -0.44 & $-1.00^{b}$ & -0.44 & -0.45 & -0.59 & -0.44 & -0.32 & -0.52 & -0.27 \\
\hline$R_{41}$ & -2.69 & -1.86 & -2.76 & -2.71 & -1.71 & -2.78 & -2.66 & $-1.23^{\mathrm{a}}$ & -2.72 & -2.53 & $-3.56^{b}$ & -2.56 & -2.57 & -3.12 & -2.57 & -2.36 & -2.97 & -2.27 \\
\hline$R_{51}$ & 0.79 & 0.73 & 0.79 & 0.78 & 0.73 & 0.79 & 0.78 & 0.80 & 0.78 & 1.79 & $2.06^{b}$ & 1.79 & 0.85 & 0.73 & 0.85 & 1.67 & 1.92 & 1.61 \\
\hline$R_{61}$ & 2.06 & 1.84 & 2.08 & 1.99 & 1.75 & 2.01 & 1.95 & 1.65 & 1.96 & 0.81 & $-0.93^{b}$ & 0.81 & 1.76 & 1.46 & 1.77 & 0.80 & 0.86 & 0.79 \\
\hline$R_{21}^{\prime}$ & 0.29 & 0.41 & 0.28 & & & & & & & 0.26 & $0.19^{b}$ & 0.26 & & 0.53 & & & 0.44 & \\
\hline$R_{31}^{\prime}$ & -1.18 & -0.82 & -1.21 & & & & & & & -1.15 & $-0.99^{b}$ & -1.15 & & $0.07^{\mathrm{a}}$ & & & -0.66 & \\
\hline$R_{41}^{\prime}$ & -1.13 & -0.47 & -1.18 & & & & & & & -1.64 & $-0.35^{\mathrm{b}}$ & -1.63 & & $0.11^{\mathrm{a}}$ & & & $-0.66^{\mathrm{a}}$ & \\
\hline$F_{2}-R_{21} F_{1}$ & -0.79 & $-0.81^{\mathrm{a}}$ & -0.28 & -0.76 & $-0.58^{\mathrm{a}}$ & -0.24 & -0.93 & $-0.34^{\mathrm{a}}$ & -0.25 & -1.17 & $-0.62^{b}$ & -1.34 & -1.45 & $-1.29^{\mathrm{a}}$ & -1.24 & -2.06 & -1.61 & -1.20 \\
\hline$F_{3}-R_{31} \mathrm{~F}_{1}$ & -1.10 & $-0.91^{\mathrm{a}}$ & -0.62 & -1.08 & $-0.84^{\mathrm{a}}$ & -0.57 & -1.19 & $-0.53^{a}$ & -0.54 & -1.09 & $-1.89^{b}$ & -1.10 & -1.06 & -1.43 & -1.02 & -2.35 & -1.95 & -1.66 \\
\hline$F_{4}-R_{41} F_{1}$ & -0.57 & 1.05 & 0.65 & -0.44 & 1.13 & 1.09 & -1.01 & $1.21^{\mathrm{a}}$ & 0.71 & -0.81 & $-0.78^{b}$ & -1.42 & -0.27 & -0.90 & -0.85 & -2.62 & -0.36 & -1.49 \\
\hline$F_{5}-R_{51} F_{1}$ & -0.21 & -0.22 & -0.36 & -0.18 & -0.23 & -0.28 & -0.29 & -0.19 & -0.34 & 0.25 & $0.22^{b}$ & 0.42 & -0.02 & -0.05 & -0.23 & 1.58 & 0.72 & 1.04 \\
\hline$F_{6}-R_{61} F_{1}$ & 0.39 & 0.03 & -0.01 & 0.49 & 0.01 & 0.19 & 0.57 & 0.16 & 0.17 & -0.64 & $-2.60^{b}$ & -0.84 & -0.62 & -0.39 & -0.90 & -0.29 & -0.42 & -0.49 \\
\hline$F_{2}^{\prime}-R_{21}^{\prime} F_{1}^{\prime}$ & 1.42 & 1.35 & 0.71 & & & & & & & 2.30 & $2.56^{\mathrm{b}}$ & 2.36 & & 0.89 & & & 1.62 & \\
\hline$F_{3}^{\prime}-R_{31}^{\prime} F_{1}^{\prime}$ & 5.47 & 4.97 & 3.51 & & & & & & & 6.64 & $5.42^{\mathrm{b}}$ & 6.77 & & $1.36^{\mathrm{a}}$ & & & 5.75 & \\
\hline$F_{4}-R_{41}^{\prime} F_{1}^{\prime}$ & 6.24 & 6.25 & 2.10 & & & & & & & 5.99 & $3.52^{b}$ & 4.33 & & $1.72^{\mathrm{a}}$ & & & $5.55^{\mathrm{a}}$ & \\
\hline
\end{tabular}

Correlation coefficient $R^{2}<0.9$

b Value defined by only two values (Nd, Eu). 
Table 2

Comparison of calculated $R_{a b}$ and $\left(F_{a}-R_{a b} F_{b}\right)$ parameters for the $[\mathrm{Ln}(\mathrm{DOTP})]^{5-}(\mathrm{pH} 10)$ chelates $(\mathrm{Ce}-\mathrm{Yb})$ directly using the graphical method based on Eq. (5) and indirectly using the parameters obtained from Eq. (2) in Table 1S

\begin{tabular}{lrl}
\hline Parameter & Eq. (5) & From Eq. (2) data \\
\hline$R_{21}$ & -0.52 & -0.56 \\
$R_{31}$ & -0.42 & -0.45 \\
$R_{41}$ & -2.69 & -2.53 \\
$R_{51}$ & 0.79 & 0.74 \\
$R_{61}$ & 2.06 & 1.93 \\
$R_{21}^{\prime}$ & 0.29 & 0.30 \\
$R_{31}^{\prime}$ & -1.18 & -1.13 \\
$R_{41}^{\prime}$ & -1.13 & -1.07 \\
$F_{2}-R_{21} F_{1}$ & -0.79 & -0.61 \\
$F_{3}-R_{31} F_{1}$ & -1.10 & -0.86 \\
$F_{4}-R_{41} F_{1}$ & -0.57 & -0.67 \\
$F_{5}-R_{51} F_{1}$ & -0.21 & -0.14 \\
$F_{6}-R_{61} F_{1}$ & 0.39 & 0.45 \\
$F_{2}^{\prime}-R_{21}^{\prime} F_{1}^{\prime}$ & 1.42 & 1.81 \\
$F_{3}^{\prime}-R_{31}^{\prime} F_{1}^{\prime}$ & 5.47 & 4.50 \\
$F_{4}^{\prime}-R_{41}^{\prime} F_{1}^{\prime}$ & 6.24 & 5.15 \\
\hline
\end{tabular}

on LIS values for one nucleus, provides some degree of confidence to the the conclusion reached. It is also not surprising that the later methods give better $A F$ values, as the slopes and intercepts used in these cases to obtain $\Delta_{\alpha, i}^{\mathrm{cal}}$ and $y_{a, i}^{\mathrm{cal}}$ came from linear regressions with much better $R^{2}$ values.

There are two major differences between Eqs. (1)-(3) and (4)-(5): (a) the parameter $A_{2}^{0}\left\langle r^{2}\right\rangle D$, which is included in the former, is factored out in the latter; (b) the quantity, $G$, which appears in the former, is converted in a ratio, $R$, in the latter. Considering these differences, the better fit exhibited by the latter models can be attributed to (1) $A_{2}^{0}\left\langle r^{2}\right\rangle$, which may vary along the lanthanide series [21]; (2) $D$, which may deviate from the theoretical values calculated by Bleaney with the assumption of an arbitrary crystal field [15]; and (3) the lanthanide contraction effect, which may be significantly reduced by Eqs. (4)-(5). Still, as discussed above, most of the plots obtained according to Eq. (5) (see Fig. 2(B))
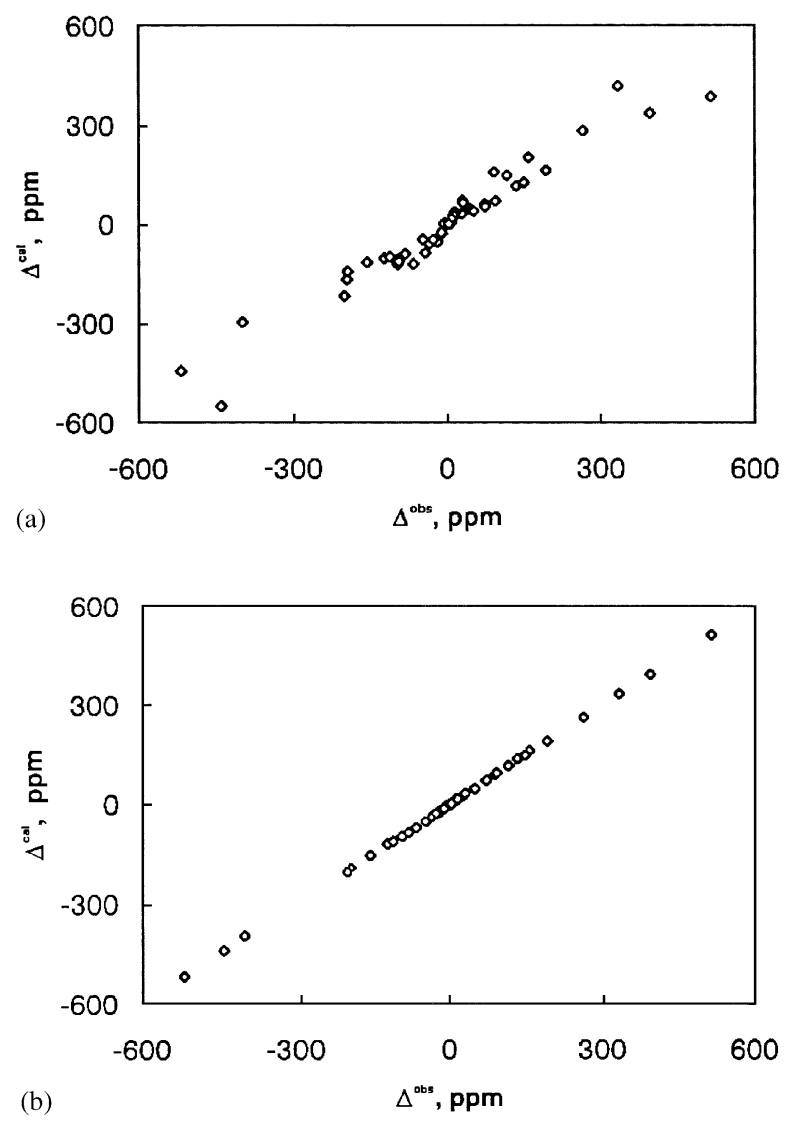

Fig. 3. Plots of $\Delta^{\text {obs }}$ vs. $\Delta^{\text {cal }}$ for [ $\left.\operatorname{Ln}(\mathrm{DOTP})\right]$ (pH 10), using (A) Eq. (1) and (B) Eq. (4).

show significant breaks at the middle of the lanthanide series, indicating that both $F_{a}$ and $R_{a b}$ parameters, constant in each lanthanide half-series, change abruptly in the middle of the series, together with changes of $A_{2}^{0}\left\langle r^{2}\right\rangle[21,26,32,35]$. These breaks could again become more apparent in part due to the magnifying effect of the division by $\left\langle S_{z}\right\rangle$, a parameter which is relatively large for $\mathrm{Gd}-\mathrm{Er}$ relative to the other paramagnetic lanthanide ions, underweighting their data somewhat.

The $R_{a b}$ values evaluated for the $\mathrm{H}_{1}-\mathrm{H}_{6}$ protons of the complexes, with $\mathrm{H}_{1}$ as reference, and the $R_{a b}^{\prime}$ ratios for the $\mathrm{C}_{1}-\mathrm{C}_{4}$ carbons $\left(\mathrm{C}_{4}\right.$ replaced by $\mathrm{P}$ atom in

Table 3

Comparison of $A F(y)$ and $A F(\Delta)$ values obtained for $[\operatorname{Ln}(\mathrm{DOTP})]^{5-}(\mathrm{pH} 10),[\operatorname{Ln}(\mathrm{DOTA})]^{-}(\mathbf{M}$ and $\mathbf{m})$ and $[\operatorname{Ln}(\mathrm{DOTEA})]^{3+}$

\begin{tabular}{|c|c|c|c|c|c|}
\hline & Eq. (1) & Eq. (2) & Eq. (3) & Eq. (4) & Eq. (5) \\
\hline \multicolumn{6}{|l|}{$A F(\Delta)$} \\
\hline$[\operatorname{Ln}(\mathrm{DOTP})]^{5-}$ & 0.23 & 1.14 & 0.31 & 0.01 & 0.14 \\
\hline$[\operatorname{Ln}(\mathrm{DOTA})]^{-}(\mathrm{M})$ & 0.22 & 0.61 & 0.29 & 0.04 & 0.41 \\
\hline$[\operatorname{Ln}(\mathrm{DOTA})]^{-}(\mathrm{m})$ & 0.24 & 0.31 & 0.36 & 0.03 & 0.04 \\
\hline$[\operatorname{Ln}(\text { DOTEA })]^{3+}$ & 0.35 & 0.44 & 0.47 & 0.03 & 0.08 \\
\hline \multicolumn{6}{|l|}{$A F(y)$} \\
\hline$[\operatorname{Ln}(\mathrm{DOTP})]^{5-}$ & 0.23 & 0.41 & 0.42 & 0.01 & 0.06 \\
\hline$[\operatorname{Ln}(\mathrm{DOTA})]^{-}(\mathrm{M})$ & 0.22 & 0.23 & 0.26 & 0.04 & 0.28 \\
\hline$[\operatorname{Ln}(\mathrm{DOTA})]^{-}(\mathrm{m})$ & 0.24 & 0.24 & 0.36 & 0.03 & 0.17 \\
\hline$[\operatorname{Ln}(\text { DOTEA })]^{3+}$ & 0.35 & 0.35 & 0.45 & 0.03 & 0.15 \\
\hline
\end{tabular}


$[\operatorname{Ln}(\mathrm{DOTP})])$, with $\mathrm{C}_{1}$ as reference, also evaluated in some of the cases, are listed in Table 1 . The values of the individual hyperfine coupling constants $F_{a}$ could not be obtained, because their values from Table $1 \mathrm{~S}$ indicate that none of the nuclei has a zero value of that parameter. Considering the $\mathrm{Ln}=\mathrm{Ce}-\mathrm{Yb}$ and $\mathrm{Ln}=$ $\mathrm{Tb}-\mathrm{Yb}$ data, where good correlation coefficients were obtained and enough data were always available, the sign of $R_{a 1}$ is different for the $\mathrm{H}_{1}, \mathrm{H}_{5}$ and $\mathrm{H}_{6}$ relative to $\mathrm{H}_{2}, \mathrm{H}_{3}$ and $\mathrm{H}_{4}$, and of $\mathrm{C}_{1}$ and $\mathrm{C}_{2}$ relative to $\mathrm{C}_{3}$ and $\mathrm{C}_{4}(\mathrm{P})$, showing that these two groups of protons and carbon/phosphorus nuclei have distinct locations in the complexes relative to the dipolar shift cone defined by $3 \cos ^{2} \theta=1$. The absolute magnitude of the ring $R_{a 1}$ ratios follows the order: $\mathrm{H}_{4}>\mathrm{H}_{1}>\mathrm{H}_{2}>\mathrm{H}_{3}$ for the DOTP and DOTEA complexes, and $\mathrm{H}_{4}>\mathrm{H}_{1}>\mathrm{H}_{3}>\mathrm{H}_{2}$ for the $\mathbf{M}$ and $\mathbf{m}$ isomers of the DOTA complexes. The acetate proton ratios also differ significantly, with $\mathrm{H}_{5}>$ $\mathrm{H}_{6}$ for the DOTA (M) and DOTEA complexes, and $\mathrm{H}_{6}>\mathrm{H}_{5}$ for the DOTA (m) and DOTP complexes.
Although the proton shifts of the [Ln(DOTP)] complexes are significantly $\mathrm{pH}$ dependent, with a decrease of the dipolar shifts when the $\mathrm{pH}$ drops from 10 to 3 (Table $2 \mathrm{~S}$ ), the four protonation steps undergone by the phosphonate groups at their unbound oxygens [28] do not cause a variation of the complex geometry, as the $R_{a 1}$ are nearly invariant from $\mathrm{pH} 10$ to $3(< \pm 4 \%)$. Such large decreases of dipolar shifts with $\mathrm{pH}$ decrease are then attributed to changes of the crystal field parameter $A_{2}^{0}\left\langle r^{2}\right\rangle$ upon protonation.

It is also interesting to compare the experimental and calculated $R_{a 1}$ values for each proton in the four complexes studied (Table 4), in particular for the two isomers of $[\operatorname{Ln}(\mathrm{DOTA})]^{-}, \mathbf{M}$ and $\mathbf{m}$, which result from different arrangements of the four pendant arms around the Ln ion with the ring conformation fixed $[26,31,35]$. These ratios are quite constant for the ring protons in all complexes, in accordance with very similar macrocyclic ring conformations. The differences between $\mathbf{M}$ and $\mathbf{m}$ forms occur in the $\mathrm{H}_{5}$ and $\mathrm{H}_{6}$ protons of the pendant

Table 4

Comparison of experimental and calculated geometric ratios $R_{a 1}$ for $\mathrm{H}_{1}-\mathrm{H}_{6}$ protons of $[\operatorname{Ln}(\mathrm{DOTA})]^{-}(\mathbf{M} \text { and m), [Ln(DOTEA)] }]^{3+}$ and $[\operatorname{Ln}(\mathrm{DOTP})]^{5-}$

\begin{tabular}{|c|c|c|c|c|c|c|c|}
\hline & & $\mathrm{H}_{1}$ & $\mathrm{H}_{2}$ & $\mathrm{H}_{3}$ & $\mathrm{H}_{4}$ & $\mathrm{H}_{5}$ & $\mathrm{H}_{6}$ \\
\hline \multirow[t]{2}{*}[\operatorname{Ln}(\mathrm{DOTA})]{$^{-}(\mathrm{M})$} & Experimental $^{\mathrm{a}}$ & 1.00 & -0.31 & -0.44 & -2.56 & 1.79 & 0.81 \\
\hline & Calculated $^{\mathrm{a}}$ & 1.00 & -0.41 & -0.45 & -2.73 & 1.82 & 0.86 \\
\hline \multirow[t]{2}{*}[\operatorname{Ln}(\mathrm{DOTA})]{$^{-}(\mathrm{m})$} & Experimental $^{\mathrm{a}}$ & 1.00 & -0.37 & -0.44 & -2.57 & 0.85 & 1.77 \\
\hline & Calculated ${ }^{\mathrm{a}}$ & 1.00 & -0.26 & -0.29 & -2.26 & 0.89 & 1.63 \\
\hline \multirow[t]{2}{*}[\operatorname{Ln}(\text{DOTEA})]{$^{3+}$} & Experimental $^{\mathrm{b}}$ & 1.00 & -0.33 & -0.27 & -2.27 & 1.61 & 0.79 \\
\hline & Calculated ${ }^{\mathrm{b}}$ & 1.00 & -0.35 & -0.27 & -2.29 & 1.65 & 0.79 \\
\hline$[\operatorname{Ln}(\mathrm{DOTP})]^{5-}$ & Experimental $^{\mathrm{c}}$ & 1.00 & -0.54 & -0.44 & -2.76 & 0.79 & 2.08 \\
\hline$\left(\mathbf{M}^{\prime}\right)$ & Calculated ${ }^{\mathrm{d}}$ & 1.00 & -0.65 & -0.51 & -3.15 & 2.29 & 0.92 \\
\hline$\left(\mathbf{m}^{\prime}\right)$ & Calculated $^{\mathrm{d}}$ & 1.00 & -0.63 & -0.46 & -2.89 & 0.87 & 2.41 \\
\hline
\end{tabular}

a $[31]$.

b $[35]$.

c $[26]$.

d Calculated in this work for models of $\mathbf{M}^{\prime}$ and $\mathbf{m}^{\prime}$ structures. The $\mathbf{m}^{\prime}$ structure was obtained based on the crystal structure of [Tm(DOTP)] [27] and the $\mathbf{M}^{\prime}$ structure by changing $\mathbf{m}^{\prime}$ to give a twist angle of $+39^{\circ}$.

Table 5

Comparison of experimental and calculated $\mathrm{Yb}-\mathrm{H}$ distances for $\mathrm{H}_{1}-\mathrm{H}_{6}$ protons of $[\operatorname{Ln}(\mathrm{DOTA})]^{-}(\mathbf{M}$ and $\mathbf{m}),[\operatorname{Ln}(\mathrm{DOTEA})]^{3+}$ and $[\operatorname{Ln}(\mathrm{DOTP})]^{5-}$, normalized to $\mathrm{H}_{1}$

\begin{tabular}{|c|c|c|c|c|c|c|c|}
\hline & & $\mathrm{H}_{1}$ & $\mathrm{H}_{2}$ & $\mathrm{H}_{3}$ & $\mathrm{H}_{4}$ & $\mathrm{H}_{5}$ & $\mathrm{H}_{6}$ \\
\hline \multirow[t]{2}{*}[\operatorname{Ln}(\mathrm{DOTA})]{$^{-}(\mathrm{M})$} & Experimental $^{\mathrm{a}}$ & 1.00 & 1.19 & 1.21 & 0.96 & 1.04 & 1.16 \\
\hline & Calculated $^{\mathrm{a}}$ & 1.00 & 1.17 & 1.17 & 0.99 & 0.99 & 1.15 \\
\hline \multirow[t]{2}{*}{ [Ln(DOTA)](m) } & Experimental $^{\mathrm{a}}$ & 1.00 & 1.17 & 1.19 & 0.95 & 1.02 & 1.05 \\
\hline & Calculated $^{\text {a }}$ & 1.00 & 1.17 & 1.17 & 0.99 & 0.99 & 0.98 \\
\hline \multirow[t]{2}{*}[\operatorname{Ln}(\text{DOTEA})]{$^{3+}$} & Experimental $^{\mathrm{b}}$ & 1.00 & 1.13 & 1.13 & 0.90 & 1.01 & 1.19 \\
\hline & Calculated ${ }^{\mathrm{b}}$ & 1.00 & 1.19 & 1.19 & 0.99 & 0.98 & 1.16 \\
\hline$[\operatorname{Ln}(\mathrm{DOTP})]^{5-}$ & Experimental $^{\mathrm{c}}$ & 1.00 & 1.16 & 1.16 & 0.95 & 1.22 & 0.98 \\
\hline$\left(\mathbf{M}^{\prime}\right)$ & Calculated $^{\mathrm{d}}$ & 1.00 & 1.19 & 1.19 & 1.01 & 0.96 & 1.17 \\
\hline$\left(\mathbf{m}^{\prime}\right)$ & Calculated $^{\mathrm{d}}$ & 1.00 & 1.21 & 1.21 & 1.04 & 1.18 & 0.93 \\
\hline
\end{tabular}

\footnotetext{
${ }^{\mathrm{a}}[31]$.

b [35].

c [26].

${ }^{\mathrm{d}}$ Calculated in this work for models of $\mathbf{M}^{\prime}$ and $\mathbf{m}^{\prime}$ structures.
} 
arms, with very good agreement of experimental and calculated data for the $[\operatorname{Ln}(\mathrm{DOTA})]^{-}$complexes (also with the X-ray results) $[36,41]$ and for the $[\operatorname{Ln}(\text { DOTEA })]^{3+}$ complexes, where the calculated structure is $M$ [35]. In the case of the $[\operatorname{Ln}(\mathrm{DOTP})]^{5-}$ complexes, the reassignment of these protons indicates that they have a $\mathbf{m}^{\prime}$ solution conformation, in agreement with calculated values for models of the $\mathbf{M}^{\prime}$ and $\mathbf{m}^{\prime}$ conformations and with the X-ray crystal structure [27].

Further information about the structure of these macrocyclic complexes is provided by Table 5, which gives the experimental relative $\mathrm{Yb}-\mathrm{H}$ distance values, obtained using the proton relaxation times from the literature $[21,26,30-32,35]$, by the following equation:

$r_{H j} / r_{H 1}=\left(T_{i, H 1} / T_{i, H j}\right)^{1 / 6} \quad i=1,2$

The relative distances obtained by Eq. (8) should be independent of the electronic spin relaxation time, rotational correlation time and magnetic moment of each individual complex $[1,30]$. Table 5 also shows the relative distances calculated for the $\mathbf{M}$ and $\mathbf{m} / \mathbf{m}^{\prime}$ forms of the $[\operatorname{Ln}(\text { DOTA })]^{-}$complexes [31] and the $\mathbf{M}$ form of the $[\operatorname{Ln}(\text { DOTEA })]^{3+}$ complex. The data in Table 4 shows that there is no significant difference in the relative distances of the four ring protons to the metal among all these $\mathrm{Yb}$ complexes, which also agree with the calculated values. For all these complexes, the axial proton, $\mathrm{H}_{4}$, has the shortest distance form $\mathrm{Yb}^{3+}$, followed by the other axial ring proton, $\mathrm{H}_{1}$, and the two equatorial ring protons, $\mathrm{H}_{2}$ and $\mathrm{H}_{3}$, which have equal $\mathrm{Yb}-\mathrm{H}$ distances. Due to their different arrangements of the pendant acetate arms around the $\mathrm{Yb}$ ion, the calculated $\mathrm{Yb}-\mathrm{H}$ distances of the pendant arm protons $\mathrm{H}_{5}$ and $\mathrm{H}_{6}$ in the $\mathbf{M}$ and $\mathbf{m} / \mathbf{m}^{\prime}$ forms differ quite substantially: while $\mathrm{H}_{5}$ is closer to $\mathrm{Yb}$ than $\mathrm{H}_{6}$ in $\mathbf{M}$, their distances to $\mathrm{Yb}$ are about the same in $\mathbf{m} / \mathbf{m}^{\prime}$. The experimental results for the $[\operatorname{Ln}(\text { DOTA })]^{-} \mathbf{M}$ and $\mathbf{m} / \mathbf{m}^{\prime}$ isomers agree very well with the predicted values [31], and the experimental results for the $[\operatorname{Ln}(\text { DOTEA })]^{3+}$ complex agrees with a $\mathbf{M}$ form in solution [35]. In the case of $[\operatorname{Ln}(\mathrm{DOTP})]^{5-}$, the experimental data also agrees with the values calculated for a $\mathbf{m}^{\prime}$ form.

Several lanthanide complexes with tetraazadodecanebased ligands have been studied by X-ray diffraction techniques in the crystal form. These complexes include $\left[\mathrm{Ln}(\mathrm{DOTA})\left(\mathrm{H}_{2} \mathrm{O}\right)\right]^{-}(\mathrm{Ln}=\mathrm{La}, \mathrm{Eu}, \mathrm{Gd}, \mathrm{Y}$ and $\mathrm{Lu})[36-$ 42], $[\mathrm{Tm}(\text { DOTP })]^{5-} \quad[22], \quad\left[\operatorname{Ln}(\text { DOTAM })\left(\mathrm{H}_{2} \mathrm{O}\right)\right]^{3+}$ $(\mathrm{Ln}=\mathrm{La}, \quad \mathrm{Eu}) \quad[43,44]$ and $\left[\operatorname{Ln}(\text { DTMA })\left(\mathrm{H}_{2} \mathrm{O}\right)\right]^{3+}$ $\left(\mathrm{Ln}=\mathrm{Gd}\right.$, Dy) $[45,46]$, with $\mathbf{M}, \mathbf{m}$ and $\mathbf{m}^{\prime}$ structures. A comparison of the available structural data indicates that the bond lengths of the $\mathrm{Ln}-\mathrm{O}$ and $\mathrm{Ln}-\mathrm{N}$ distances are $2.67 \pm 0.02$ and $2.38 \pm 0.04 \AA$, almost independent of the lanthanide ion and the ligand. The distance between the lanthanide ion and the plane formed by the four ring nitrogens also falls in a narrow range from 1.64 to 1.68
$\AA$ for all these complexes. This suggests that the conformation of the tetraazacyclododecane ring and the geometry of the pyramid formed by the lanthanide ion and the four nitrogen atoms remain the same in solution.

In summary, the present work shows that the crystalfield independent method based on Eqs. (4)-(5) is superior to the classical method based on Eqs. (1)-(3). Since Eqs. (4)-(5) provide $G$ ratios rather than $G$ values, the effect of lanthanide contraction is reduced. Most important, they do not contain $A_{2}^{0}\left\langle r^{2}\right\rangle$ values, making this method especially suitable for describing LIS data when there is a variation of the crystal field parameter along a lanthanide series of complexes. Comparison of the LIS data available for the axially symmetric complexes [Ln(DOTA) $]^{-}$(M and $\mathbf{m}$ isomers), $[\operatorname{Ln}(\text { DOTP })]^{5-}$ and $[\operatorname{Ln}(\text { DOTEA })]^{3+}$ by the two methods shows that the breaks in plots observed using the classical method are still present in the plots by the crystal-field independent method, although they are much less significant, showing that both the hyperfine coupling constants and the ratios of geometric terms change at the middle of the lanthanide series. Analysis of the proton shifts of [ $\mathrm{Ln}(\mathrm{DOTP})]$ complexes at $\mathrm{pH} 10$, 7 and 3 indicates that protonation of the complexes results in a decrese on the crystal field coefficient.

\section{Supplementary material}

Table 1S, with the LIS values for [Ln(DOTA) $]^{-}$and $[\operatorname{Ln}(\text { DOTEA })]^{3+}$; Table $2 \mathrm{~S}$, with the calculated $F_{a}$ and $A_{2}^{0}\left\langle r^{2}\right\rangle G_{a}$ parameters for the $\mathrm{Ln}^{3+}$ chelates using the graphical method based on Eq. (2) are avaible as supplementary tables from the author on request.

\section{Acknowledgements}

This research was supported by grants from the Robert A. Welch Foundation (AT-584), the National Institutes of Health Biotechnology Research Program (RR-02584) and Fundação para a Ciência e Tecnologia, Portugal (PRAXIS 2/2.1/SAU/1194/96). We thank Dr. Elsa Henriques, from the University of Porto, Portugal, for help in obtaining computer molecular models of the $\mathbf{M}^{\prime}$ and $\mathbf{m}^{\prime}$ forms of $[\operatorname{Ln}(\mathrm{DOTP})]$ and the respective computed ratios of geometric $G$ values and protonmetal distances.

\section{References}

[1] J.A. Peters, J. Huskens, D.J. Raber, Progr. NMR Spectrosc. 28 (1996) 283. 
[2] D.J. Raber, Lanthanide Shift Reagents in Stereochemical Analysis (Chapter 6), VCH, New York, 1983.

[3] J.A. Peters, E. Zitha-Bovens, D.M. Corsi, C.F.G.C. Geraldes, in: A.E. Merbach, É. Tóth (Eds.), The Chemistry of Contrast Agents in Medical Magnetic Resonance Imaging (chapter 8), Wiley, Chichester, 2001.

[4] J. Reuben, J. Chem. Soc., Dalton Trans. (1979) 68.

[5] M.C. Alpoim, A.M. Urbano, C.F.G.C. Geraldes, J.A. Peters, J. Chem. Soc., Dalton Trans. (1992) 463.

[6] C.C. Hinckley, J. Am. Chem. Soc. 91 (1969) 5160

[7] D.C. Buster, M.M.C.A. Castro, C.F.G.C. Geraldes, C.R. Malloy, A.D. Sherry, T.C. Siemers, Magn. Reson. Med. 15 (1990) 25.

[8] C.R. Malloy, D.C. Buster, M.M.C.A. Castro, C.F.G.C. Geraldes, F.M.H. Jeffrey, A.D. Sherry, Magn. Reson. Med. 15 (1990) 33.

[9] S. Aime, M. Botta, M. Fasano, E. Terreno, P. Kinchesh, L. Calabi, L. Paleari, Magn. Reson. Med. 35 (1996) 648.

[10] C.S. Zuo, K.R. Metz, Y. Sun, A.D. Sherry, J. Magn. Reson. 133 (1998) 53.

[11] M. Henschel, M. Findeisen, W. Schmidt, T. Frenzel, W. Wlodarczyk, P. Wust, R. Felix, Magn. Reson. Matl. Phys. Bio. Med. 10 (2000) 52.

[12] W. de W. Horrocks, Jr., J.P. Sipe, III, Science 177 (1972) 994

[13] R.M. Goding, M.P. Halton, Aust. J. Chem. 25 (1972) 2577.

[14] R.M. Golding, P. Pyykkö, Mol. Phys. 26 (1973) 1389.

[15] B. Bleaney, J. Magn. Reson. 8 (1972) 91

[16] A.A. Pinkerton, M. Rossier, S. Spiliadis, J. Magn. Reson. 64 (1985) 420

[17] C.M. Dobson, R.J.P. Williams, A.V. Xavier, J. Chem. Soc., Dalton Trans. (1973) 2662

[18] (a) C.N. Reilley, B.W. Good, J.F. Desreux, Anal. Chem. 47 (1975) 2110

(b) C.N. Reilley, B.W. Good, R.D. Allendoerfer, Anal. Chem. 48 (1976) 1446

[19] J.A. Peters, J. Magn. Reson. 68 (1986) 240.

[20] J. Reuben, J. Magn. Reson. 50 (1982) 233.

[21] J. Ren, A.D. Sherry, J. Magn. Reson. B 111 (1996) 178.

[22] C. Platas, F. Avecilla, A. de Blas, C.F.G.C. Geraldes, T. Rodriguez-Blas, H. Adams, J. Mahia, Inorg. Chem. 38 (1999) 3190.

[23] S. Rigault, C. Piguet, J.-C.G. Bünzli, J. Chem. Soc., Dalton Trans. (2000) 2045.

[24] S. Rigault, C. Piguet, J. Am. Chem. Soc. 122 (2000) 9304.

[25] P. Caravan, J.J. Ellison, T.J. McMurry, R.B. Lauffer, Chem. Rev. 9 (1999) 2293.

[26] C.F.G.C. Geraldes, A.D. Sherry, G.E. Kiefer, J. Magn. Reson. 97 (1992) 290
[27] E.F. Paulus, P. Juretschke, J. Lang, 3 Jahrestag der Deutschen Gesellschaft für Kristallographie, Darmstadt, 1995.

[28] A.D. Sherry, J. Ren, J. Huskens, E. Brücher, É. Tóth, C.F.G.C. Geraldes, M.M.C.A. Castro, W.P. Cacheris, Inorg. Chem. 35 (1996) 4604

[29] J.F. Desreux, Inorg. Chem. 19 (1980) 1319.

[30] S. Aime, L. Barbero, M. Botta, G. Ermondi, J. Chem. Soc., Dalton Trans. (1992) 225

[31] S. Aime, M. Botta, G. Ermondi, Inorg. Chem. 31 (1992) 4291.

[32] M.P.M. Marques, C.F.G.C. Geraldes, A.D. Sherry, A.E. Merbach, H. Powell, D. Pubanz, S. Aime, M. Botta, J. Alloys Compounds 225 (1995) 303

[33] S. Aime, M. Botta, M. Fasano, M.P.M. Marques, C.F.G.C. Geraldes, D. Pubanz, A.E. Merbach, Inorg. Chem. 36 (1997) 2059.

[34] S. Hoeft, K. Roth, Chem. Ber. 126 (1993) 869.

[35] J.H. Forsberg, R.M. Delaney, Q. Zhao, G. Harakas, R. Chandran, Inorg. Chem. 34 (1995) 3705

[36] M.-R. Spirlet, J. Rebizant, J.F. Desreux, M.-F. Loncin, Inorg. Chem. 23 (1984) 359.

[37] D. Parker, K. Pulukkody, F.C. Smith, A. Batsanov, J.A.K. Howard, J. Chem. Soc., Dalton Trans. (1994) 689.

[38] S. Aime, A. Barge, M. Botta, M. Fasano, J.D. Ayala, G. Bombieri, Inorg. Chim. Acta 246 (1996) 423.

[39] J.P. Dubost, J.M. Leger, M.H. Langlois, D. Meyer, M.C.R. Schaefer, Academie Sci. Ser II Univ. 312 (1991) 329.

[40] C.A. Chang, L.C. Francesconi, M.F. Malley, K. Kumar, J.Z. Gougoutas, M.F. Tweedle, D.W. Lee, L.J. Wilson, Inorg. Chem. 32 (1993) 3501

[41] F. Benetollo, G. Bombieri, S. Aime, M. Botta, Acta Crystallogr. C55 (1999) 353

[42] S. Aime, A. Barge, F. Benetollo, G. Bombieri, M. Botta, F. Uggeri, Inorg. Chem. 36 (1997) 4287.

[43] J.R. Morrow, S. Amin, C.H. Lake, M.R. Churchill, Inorg. Chem. 32 (1993) 4566

[44] S. Amin, J.R. Morrow, C.H. Lake, M.R. Churchill, Angew. Chem., Int. Ed. Engl. 33 (1994) 773.

[45] A. Bianchi, L. Calabi, C. Giorgi, P. Losi, P. Mariani, P. Paoli, P. Rossi, B. Valtancoli, M. Virtuani, J. Chem. Soc., Dalton Trans. (2000) 697.

[46] S. Aime, A. Barge, J.I. Bruce, M. Botta, J.A.K. Howard, J.M. Moloney, D. Parker, A.S. de Sousa, M. Woods, J. Am. Chem. Soc. 121 (1999) 5762.

[47] (a) M.R. Willcott, R.E. Lenkinski, R.E. Davis, J. Am. Chem. Soc. 94 (1972) 1742;

(b) R.E. Davis, M.R. Willcott, J. Am. Chem. Soc. 94 (1972) 1744. 